\title{
Tobacco Consumption and Its Socio-demographic Correlates Among Adolescents Residing in Slum Areas of Bhubaneswar, India
}

\begin{abstract}
Background: Tobacco use is an emerging public health problem among adolescents worldwide. The objectives of the study were to determine the prevalence and pattern of tobacco use among adolescents and assess the factors associated with its use in urban slums of Bhubaneswar, Odisha. Materials and Methods: A community-based cross-sectional study was carried out in 11 randomly selected urban slums of Bhubaneswar during the year 2017-2018 among 297 adolescents using a pretested semi-structured schedule. Data were analyzed using SPSS version 21.0; risk analysis was done using odds ratios with $95 \%$ confidence intervals (CIs). Results: Ninety-one (30.6\%) adolescents were current tobacco users; 40 (44\%) were consuming smoking form and $67(73.6 \%)$ smokeless form. Betel quid was the most predominant form of smokeless tobacco $(35.8 \%)$ and the cigarette was the most common smoking form (55\%) used. Only $16.5 \%$ of adolescents had tried to quit tobacco during the past year, whereas $65.9 \%$ showed a desire to quit tobacco in future. Multivariate analysis revealed that tobacco use was significantly associated with older age(adjusted odds ratio [aOR]: 5.5; 95\% CI: 2.8-10.6), male gender (aOR: 5.9; 95\% CI: 2.9-12.0), employment (aOR: 7.4; 95\% CI: 3.6-15.4), illiterate mother (aOR: 3.3 ; 95\% CI: 1.7-6.3), tobacco use by family member (aOR: 3.7 ; 95\% CI: 2.0-6.9), tobacco use by peers (aOR: 6.5; 95\% CI: 2.9-14.3), and easy accessibility (aOR: 4.1; 95\% CI: 1.5-11.2). Conclusion: The prevalence of tobacco use was high among adolescents of slums in Bhubaneswar. Existing schemes for controlling the tobacco epidemic among slum adolescents could be strengthened by incorporating these determinants.
\end{abstract}

Keywords: Adolescents, slums, smoked tobacco, smokeless tobacco, tobacco use

\section{Introduction}

Tobacco use is one of the biggest public health threats throughout the world and responsible for not only the loss of human lives but also leads to heavy social and economic costs. ${ }^{[1]}$ Worldwide, more than 7 million people are killed each year due to the use of tobacco products. If the current trend of tobacco use continues, more than 8 million people will die every year from diseases related to tobacco use by $2030 .^{[2,3]}$ Adolescence is a period of considerable risk during which adolescents become vulnerable to high-risk behaviors and initiate tobacco use. It is well established that most of adult tobacco users start tobacco use in adolescence. ${ }^{[4,5]}$ According to a global youth tobacco survey in India, $14.6 \%$ of adolescents aged 13-15 years were currently using any tobacco product; $19 \%$ of boys and $8.3 \%$ of girls were tobacco users. ${ }^{[6]}$ The most prevalent form of tobacco use in India

This is an open access journal, and articles are distributed under the terms of the Creative Commons Attribution-NonCommercial-ShareAlike 4.0 License, which allows others to remix, tweak, and build upon the work non-commercially, as long as appropriate credit is given and the new creations are licensed under the identical terms.

For reprints contact: WKHLRPMedknow_reprints@wolterskluwer.com is smokeless tobacco which includes khaini, gutkha, betel quid with tobacco, and zarda, whereas smoking forms of tobacco used are bidi, cigarette, and hookah. ${ }^{[7]}$

The urban-slum population is a vulnerable section of the society which fares very poorly on issues related to health and other basic amenities. It has been reported that tobacco use is rampant in urban slums in developing countries including India. ${ }^{[8,9]}$ According to the 2011 census of India, $24.4 \%$ of the total urban population was living in slum areas and the proportion of the urban-slum population is rapidly rising in the states including Odisha. ${ }^{[10]}$ The scientific literature on the prevalence and patterns of tobacco use among adolescents living in urban slums of India is scarce. The present study has been undertaken to determine the prevalence of tobacco usage and its patterns and assess the associated sociodemographic factors among the adolescents residing in slum areas of Bhubaneswar city, Odisha.

\footnotetext{
How to cite this article: Panigrahi A, Sharma D, Mohapatra I. Tobacco consumption and its sociodemographic correlates among adolescents residing in slum areas of Bhubaneswar, India. Indian J Med Paediatr Oncol 2020;41:718-23.
}

\section{Ansuman Panigrahi ${ }^{1}$, Dheeraj Sharma², Ipsa Mohapatra ${ }^{1}$}

${ }^{1}$ Department of Community Medicine, Kalinga Institute of Medical Sciences, KIIT University, Bhubaneswar, Odisha, India, ${ }^{2}$ Department of Community Medicine, Muzaffarnagar Medical College, Muzaffarnagar, Uttar Pradesh, India

Submitted: $10-A p r-2020$ Revised: 23-Apr-2020 Accepted: 03-Aug-2020 Published: 29-Oct-2020

Address for correspondence: Dr. Ansuman Panigrahi, Department of Community Medicine, Kalinga Institute of Medical Sciences, KIIT University, Bhubaneswar - 751024 , Odisha, India. E-mail:dransuman3@gmail. com

Access this article online Website: www.ijmpo.org DOI: 10.4103/ijmpo.ijmpo_151_20 Quick Response Code:

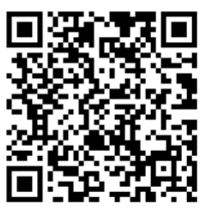




\section{Materials and Methods}

\section{Study participants and study design}

This cross-sectional study was conducted during the year 2017-2018 among the adolescents residing in selected slum areas of Bhubaneswar city, the capital city of state Odisha, India. The national estimate of the prevalence of the current use of tobacco in any form among 13- to 15-year-old adolescents was $14.6 \%{ }^{[6]}$ With an absolute precision of $5 \%$ at a $95 \%$ confidence interval (CI) and a design effect of 1.5 , the required sample size was estimated at 288. A multistage cluster random sampling technique was used to select the study areas. Bhubaneswar city is divided into three geographical zones: North, South-East, and South-West which comprise 67 wards and 436 slums. Of the three zones, the North zone was randomly selected; $50 \%$ of the wards having slum areas (11 wards) in this zone were randomly chosen, and then from each selected ward, one slum was randomly selected. The sample size was equally distributed among the selected slums. Overall, 320 adolescents aged 10-19 years living in the selected slums were approached for the study, and finally, 297 agreed to participate in the study. In each household, one adolescent was considered for the study purpose, and if more than one study subjects were found in a household, only one was selected by a simple random sampling technique.

\section{Data collection}

Before initiation of the study, all the study participants (adolescents) and their parents were informed about the purpose of the study and details of the procedure involved in the study. The adolescents gave assent and their parents provided consent before initiation of the study. We designed a semi-structured schedule based on the opinion of experts and a review of relevant literatures. Then, this schedule was pilot tested on 20 slum adolescents for its legibility and comprehensibility and the final schedule was developed after suitable modifications. The validity of all the questions in the schedule was examined by checking whether all the subjects interpreted the questions the same way or not. Using this schedule, information regarding sociodemographic characteristics such as age, gender, schooling, occupation, educational status of parents, and socioeconomic status was collected by a trained investigator. Furthermore, data on tobacco use, type of tobacco, age of initiation, frequency of use, quitting behavior, tobacco use by a family member, tobacco use by peers, knowledge regarding harmful effects of tobacco, exposure to anti-smoking media messages, etc., were collected.

\section{Ethics statement}

The study was approved by the Institutional Ethics Committee of the authors' institution (Ref. No: KIMS/ KIITIEC/115/2015), and all the procedures followed were in accordance with the ethical standards of the responsible committee on human experimentation and with the Helsinki Declaration of 1975, as revised in 2000.

\section{Statistical analysis}

All the data were scrutinized, edited, and corrected for any discrepancy and analyzed using IBM SPSS Statistics for Windows, Version 21.0. (Armonk, NY: IBM Corp.) and expressed as percentages, odds ratio, and 95\% CI. Estimates of the prevalence of all forms of tobacco (smoked or smokeless) use were computed. The outcome measure was the "current tobacco use in any form" and the correlates of tobacco use were independently assessed using univariate logistic regression. The variables which had $P<0.1$ in univariate analyses were included in the multivariate logistic regression models. Due to the complex sampling design of the study, the sample data were weighted to get a true representation of the population. The collinearity between the variables was also checked. $P<0.05$ was considered statistically significant.

\section{Results}

As revealed in our study, the overall point prevalence of current tobacco use among slum adolescents was $30.6 \%(91 / 297)$. Among the respondents, tobacco use was seen in $58.1 \%$ of the boys and $9.5 \%$ of the girls [Table 1 ]. The mean ages of the boys and the girls were found to be $14.9( \pm 2.9)$ years and $15.0( \pm 2.9)$ years, respectively. The mean age of initiation of tobacco use was $12.2( \pm 3.2)$ years for boys and $11.0( \pm 3.0)$ years for girls. The multivariate logistic regression model revealed that age, gender, occupational status, maternal education, tobacco use by a family member, tobacco use by peers, and easy accessibility were the significant predictors of tobacco use behavior among slum adolescents [Table 2].

Among the current tobacco users, 40 (44\%) used the smoked form and $67(73.6 \%)$ used the smokeless form. The cigarette was the most common form of tobacco used (55\%), whereas bidi was initiated at an earlier age as compared to other tobacco forms [Table 3]. Concerning the quitting behavior, only $15(16.5 \%)$ adolescents reported that they had tried to quit tobacco during the past year, whereas almost two-third of them showed a desire to quit tobacco in future. Table 4 reveals that around $82.5 \%$ believed that "tobacco smoking causes serious illness," as high as $80.5 \%$ agreed that "smokeless tobacco can cause serious illness" too. Less than half of the respondents informed that they had noticed anti-smoking and anti-smokeless media messages in the past 30 days, newspaper and television being cited as the most common sources of information.

\section{Discussion}

In this cross-sectional study, the prevalence of current tobacco use among slum adolescents of Bhubaneswar was observed as $30.6 \%$. In a study by Bardhan et al. among adolescent slum dwellers of Guwahati, the prevalence was 
Table 1: Univariate analyses showing the association of various factors with the current tobacco use among slum adolescents $(n=297)$

\begin{tabular}{|c|c|c|c|c|c|}
\hline \multirow[t]{2}{*}{ Characteristics } & \multicolumn{3}{|c|}{ Prevalence of current tobacco use, Frequency (\%) } & \multirow[t]{2}{*}{ Total surveyed } & \multirow[t]{2}{*}{$\boldsymbol{P}$} \\
\hline & Smoked & Smokeless & Any form & & \\
\hline \multicolumn{6}{|l|}{ Age in years } \\
\hline$<15$ & $16(10.6)$ & $25(16.6)$ & $33(21.9)$ & 151 & 0.001 \\
\hline$\geq 15$ & $24(16.4)$ & $42(28.8)$ & $58(39.7)$ & 146 & \\
\hline \multicolumn{6}{|l|}{ Gender } \\
\hline Male & $38(22.6)$ & $53(31.5)$ & $75(58.1)$ & 129 & 0.000 \\
\hline Female & $2(1.6)$ & $14(10.9)$ & $16(9.5)$ & 168 & \\
\hline \multicolumn{6}{|l|}{ Schooling } \\
\hline Attending & $3(3.0)$ & $15(15.2)$ & $18(18.2)$ & 99 & 0.001 \\
\hline Not attending & $37(18.7)$ & $52(26.3)$ & $73(36.9)$ & 198 & \\
\hline \multicolumn{6}{|l|}{ Occupation } \\
\hline Unemployed & $28(11.3)$ & $39(15.8)$ & $58(23.5)$ & 247 & 0.000 \\
\hline Employed & $12(24.0)$ & $28(56.0)$ & $33(66.0)$ & 50 & \\
\hline \multicolumn{6}{|c|}{ Education of mother } \\
\hline Illiterate & $21(19.1)$ & $29(26.4)$ & $41(37.3)$ & 110 & 0.013 \\
\hline Literate & $14(8.2)$ & $31(18.2)$ & $40(23.5)$ & 170 & \\
\hline \multicolumn{6}{|c|}{ Education of father } \\
\hline Illiterate & $14(17.5)$ & $22(27.5)$ & $31(38.8)$ & 80 & 0.062 \\
\hline Literate & $23(11.4)$ & $41(20.4)$ & $55(27.4)$ & 201 & \\
\hline \multicolumn{6}{|c|}{ Socioeconomic status* } \\
\hline Lower/LM & $26(18.3)$ & $29(20.4)$ & $45(31.7)$ & 142 & 0.117 \\
\hline Middle & $7(6.3)$ & $24(21.1)$ & $28(25.0)$ & 112 & \\
\hline UM/upper & $7(16.3)$ & $14(32.6)$ & $18(41.9)$ & 43 & \\
\hline \multicolumn{6}{|c|}{ Tobacco use by family member } \\
\hline No & $16(8.8)$ & $28(15.4)$ & $37(20.3)$ & 182 & 0.000 \\
\hline Yes & $24(20.9)$ & $39(33.9)$ & $54(47.0)$ & 115 & \\
\hline \multicolumn{6}{|c|}{ Tobacco use by peers } \\
\hline No & $13(6.3)$ & $37(18.0)$ & $44(21.5)$ & 205 & 0.000 \\
\hline Yes & $27(29.3)$ & $30(32.6)$ & $47(51.1)$ & 92 & \\
\hline \multicolumn{6}{|c|}{ Easy accessibility in respondent's area } \\
\hline No & $11(15.3)$ & $8(11.1)$ & $14(19.4)$ & 72 & 0.018 \\
\hline Yes & $29(12.9)$ & $59(26.2)$ & $77(34.2)$ & & \\
\hline
\end{tabular}

*LM - Lower middle; UM - Upper middle

a little higher (35.0\%). ${ }^{[11]}$ A lower prevalence (19.4\%) was seen in a study from Chennai city and it might be due to the wide age group taken in the study. ${ }^{[12]}$ In another study, the prevalence was quite high $(88.2 \%)$; the authors attributed this to lack of recreation facilities, lesser access to health education, and overall compromised living conditions. ${ }^{[5]}$

In the current study, older adolescents (age $\geq 15$ years) had 5.5 times higher odds of using tobacco than their younger counterparts. The reason may be because as age increases, adolescents more likely to take decisions independently and less likely to be supervised by their parents or guardians. Other studies have also shown a similar result. ${ }^{[11,12]}$ It was revealed in our study that male adolescents were almost six times more likely to use tobacco as compared to females. This might be attributed to sociocultural and behavioral differences between male and female adolescents. A higher prevalence of tobacco use among males is consistent with earlier studies. ${ }^{[5,11,12]}$ We observed in our study that tobacco usage was significantly higher among those adolescents who were employed compared to those unemployed. This can be ascertained due to the fact that when employed, one becomes financially independent, and thus, purchasing power increases. Stress due to a job can also be a reason for the same. Similar findings have been reported in earlier studies. ${ }^{[9,13]}$

In the present study, the odds of tobacco use increased 3.3 times among adolescents who had illiterate mothers than adolescents having literate mothers. This could be due to the reason that literate mothers might be practicing skills of positive parenting and communication. Counseling of children on a healthy lifestyle by the literate mothers may also be another reason for the lesser number of tobacco users. It was evident from our study that an adolescent with a family member using tobacco had higher odds of tobacco use. This finding is in corroboration with the results of other studies. ${ }^{[5,14-16]}$ In our study, the adolescents whose peers consumed tobacco were 6.5 times more likely to consume 


\begin{tabular}{|c|c|c|c|c|}
\hline \multirow[t]{2}{*}{ Characteristics } & \multicolumn{2}{|c|}{ Model 1 Current tobacco use in any form } & \multicolumn{2}{|c|}{ Model 2 Current tobacco use in any form } \\
\hline & aOR $(95 \% \mathrm{CI})$ & $P$ & aOR $(95 \% \mathrm{CI})$ & $P$ \\
\hline \multicolumn{5}{|l|}{ Age in years } \\
\hline$<15$ & 1 & 0.00 & 1 & 0.00 \\
\hline$\geq 15$ & $6.8(3.3-13.9)$ & & $5.5(2.8-10.6)$ & \\
\hline \multicolumn{5}{|l|}{ Gender } \\
\hline Female & 1 & 0.00 & 1 & 0.00 \\
\hline Male & $7.7(3.6-16.7)$ & & $5.9(2.9-12.0)$ & \\
\hline \multicolumn{5}{|l|}{ Schooling } \\
\hline Attending & 1 & 0.233 & - & \\
\hline Not attending & $1.7(0.7-4.2)$ & & & \\
\hline \multicolumn{5}{|l|}{ Occupation } \\
\hline Unemployed & 1 & 0.00 & 1 & 0.00 \\
\hline Employed & $10.8(4.4-27.0)$ & & $7.4(3.6-15.4)$ & \\
\hline \multicolumn{5}{|c|}{ Education of mother } \\
\hline Literate & 1 & 0.014 & 1 & 0.001 \\
\hline Illiterate & $4.1(1.3-12.4)$ & & $3.3(1.7-6.3)$ & \\
\hline \multicolumn{5}{|l|}{ Education of father } \\
\hline Literate & 1 & 0.829 & - & \\
\hline Illiterate & $1.1(0.4-3.6)$ & & & \\
\hline \multicolumn{5}{|c|}{ Tobacco use by family member } \\
\hline No & 1 & 0.00 & 1 & 0.00 \\
\hline Yes & $4.4(2.1-9.3)$ & & $3.7(2.0-6.9)$ & \\
\hline \multicolumn{5}{|c|}{ Tobacco use by peers } \\
\hline No & 1 & 0.00 & 1 & 0.00 \\
\hline Yes & $5.9(2.6-13.5)$ & & $6.5(2.9-14.3)$ & \\
\hline \multicolumn{5}{|c|}{ Easy accessibility in respondent's area } \\
\hline No & 1 & 0.016 & 1 & 0.006 \\
\hline Yes & $4.1(1.3-13.1)$ & 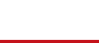 & $4.1(1.5-11.2)$ & 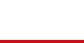 \\
\hline
\end{tabular}

\begin{tabular}{|c|c|c|c|c|c|c|}
\hline \multirow[t]{2}{*}{ Queries } & \multicolumn{2}{|c|}{ Smoked tobacco, $n$ (\%) } & \multicolumn{4}{|c|}{ Smokeless tobacco, $n(\%)$} \\
\hline & Cigarette & Bidi & Gutkha & Khaini & Betel quid & Pan masala \\
\hline What is the type of tobacco used? & $22(55.0)$ & $18(45.0)$ & $19(28.3)$ & $17(25.4)$ & $24(35.8)$ & $7(10.4)$ \\
\hline \multicolumn{7}{|l|}{$\begin{array}{l}\text { Did you try to quit tobacco in last } \\
\text { year? }\end{array}$} \\
\hline Yes & $15(16.5)$ & & & & & \\
\hline No & $76(83.5)$ & & & & & \\
\hline \multicolumn{7}{|l|}{ Will you quit tobacco in the future? } \\
\hline Yes & $60(65.9)$ & & & & & \\
\hline No & $22(24.2)$ & & & & & \\
\hline Do not know & $9(9.9)$ & & & & & \\
\hline $\begin{array}{l}\text { Average age (year) of initiation, } \\
\text { mean } \pm \mathrm{SD} \text { (range) }\end{array}$ & $13.4 \pm 2.9(9-18)$ & $10.0 \pm 2.0(8-17)$ & $\begin{array}{c}11.5 \pm 3.3 \\
(7-18)\end{array}$ & $\begin{array}{c}10.4 \pm 2.7 \\
(7-17)\end{array}$ & $\begin{array}{c}12.7 \pm 2.9 \\
(7-18)\end{array}$ & $\begin{array}{c}11.7 \pm 3.9 \\
(7-17)\end{array}$ \\
\hline $\begin{array}{l}\text { Average frequency in a day, } \\
\text { mean } \pm \text { SD (range) }\end{array}$ & $4.8 \pm 2.2(1-8)$ & $7.6 \pm 2.1(4-12)$ & $3.2 \pm 1.3(1-6)$ & $3.8 \pm 1.7(1-7)$ & $2.7 \pm 1.2(1-5)$ & $1.7 \pm 0.76(1-3)$ \\
\hline $\begin{array}{l}\text { How soon (min) after waking up do } \\
\text { you use tobacco? mean } \pm \text { SD (range) }\end{array}$ & $\begin{array}{c}50.9 \pm 21.6 \\
(20-90)\end{array}$ & $\begin{array}{c}26.4 \pm 16.3 \\
(5-60)\end{array}$ & $\begin{array}{c}46.3 \pm 30.4 \\
(5-100)\end{array}$ & $\begin{array}{c}40.6 \pm 43.1 \\
(5-180)\end{array}$ & $\begin{array}{c}64.8 \pm 43.6 \\
(5-180)\end{array}$ & $\begin{array}{c}78.6 \pm 14.6 \\
(50-90)\end{array}$ \\
\hline
\end{tabular}

$\mathrm{SD}$ - Standard deviation 


\begin{tabular}{lcc}
\hline \multicolumn{2}{c}{ Table 4: Responses to queries put across to all participants $(\boldsymbol{n}=\mathbf{2 9 7})$} \\
\hline Queries & \multicolumn{2}{c}{ Response (\%) } \\
\cline { 2 - 2 } Does tobacco smoking cause serious illness? & $245(82.5)$ & No, frequency (\%) \\
Does smokeless tobacco cause serious illness? & $239(80.5)$ & $52(17.5)$ \\
Have you noticed anti-smoking media messages during the past 30 days? & $139(46.8)$ \\
Where did you notice anti-smoking media messages* & \\
Newspaper & $85(61.1)$ \\
Television & $84(60.4)$ \\
Billboard & $50(35.9)$ \\
Radio & $44(31.6)$ \\
Magazine & $43(30.9)$ \\
Have you noticed anti-smokeless media messages during the past 30 days? & $117(39.4)$ \\
Where did you notice anti-smokeless media messages* & \\
Newspaper & $76(64.9)$ \\
Television & $71(60.7)$ \\
Billboard & $40(34.2)$ \\
Radio & $38(32.5)$ \\
Magazine & $37(31.6)$ \\
\hline
\end{tabular}

tobacco compared to those whose peers did not. Similar observations have been reported in previous studies. ${ }^{[11,17,18]}$ These findings suggest that tobacco use by family members and peers strongly influences the tobacco behavior of slum adolescents. We also found that ease of access to tobacco products in slum areas was significantly associated with higher odds of tobacco consumption among the adolescents dwelling in those areas. In an earlier study, it was shown that perceived accessibility independently contributed to the escalation of tobacco use among youths. ${ }^{[19]}$ In another survey conducted in Myanmar, the trend of tobacco use by adolescents rose with the increasing accessibility of tobacco year by year. ${ }^{[20]}$

In the present study, the majority (73.6\%) of slum adolescents were smokeless tobacco users, and most of them were using betel quid $(35.8 \%)$ and gutkha $(28.3 \%)$. Earlier studies have also shown that the smokeless form of tobacco was more commonly used by adolescents. ${ }^{[5,11]}$ The practice of use of areca nut as a custom in this part of eastern India may be a reason for easy accessibility and higher use of the smokeless form of tobacco, i.e., betel quid. The average age of initiation of smoked/smokeless tobacco ranged from 10.0 to 13.4 years, with $29.7 \%$ having initiated before 10 years of age in the present study. Das et al. also observed in their study that the age of initiation of tobacco consumption was 10-13 years, with around $22.6 \%$ had initiated tobacco use before 10 years of age. ${ }^{[5]}$ Special attention needs to be given to this age group by adopting behavioral change communication strategies to protect them from the harmful effects of tobacco in later life. We noticed in our study that almost two-third of the study participants had shown the desire to quit tobacco in future. Similar results have been reported in the global youth tobacco survey conducted in India. ${ }^{[6]}$ However, only $16.5 \%$ of slum adolescents in our study had tried to quit tobacco during last year which is in contrast to the finding of the global youth tobacco survey, in which $67.2 \%$ of adolescents had attempted to quit tobacco. ${ }^{[6]}$

Although awareness regarding the harmful effects of tobacco was high, the prevalence of tobacco use among slum adolescents of Bhubaneswar was still high. This emphasizes the need for behavioral change communication interventions, as only being aware has not helped them adopt good habits.

The cross-sectional design of the study is the main limitation that precludes us to affirm the cause-effect relationships of the significant associations. Furthermore, there might be an introduction of reporting bias as the data are based on self-reporting and recall of past experiences. However, in light of the findings of the present study and existing evidence, it is clear that tobacco control policy in India is not adequate in addressing the issue, and thus, there is a need to modify the current "cigarette and other tobacco products act" with a focus on this emerging high-risk group. More such surveys, as well as qualitative research, need to be carried out in urban slums to have an in-depth understanding of the slum community behavior toward tobacco use and identify the gaps in the implementation of the government policies.

\section{Conclusion}

The prevalence of tobacco use among adolescents residing in slums of Bhubaneswar was high. Sincere efforts are needed to strengthen the existing schemes for controlling the tobacco epidemic among slum adolescents which could be achieved by incorporating the determinants observed in the study. 


\section{Financial support and sponsorship}

Nil.

\section{Conflicts of interest}

There are no conflicts of interest.

\section{References}

1. World Health Organization. Tobacco. World Health Organization; 2019. Available from: https:/www.who.int/news-room/ fact-sheets/detail/tobacco. [Last accessed on 2019 Oct 03].

2. World Health Organization. WHO Report on the Global Tobacco Epidemic, 2017: Monitoring Tobacco use and Prevention Policies. World Health Organization; 2017. Available from: https://apps.who.int/iris/bitstream/handle/10665/255874/9789241 512824-eng.pdf; jsessionid=AEE770B121C55D3353B9BD383A FAF65E? sequence $=1$. [Last accessed on 2019 Oct 03].

3. Centers for Disease Control and Prevention. Smoking and Tobacco use; 2019. Available from: https://www.cdc.gov/ tobacco/data statistics/fact sheets/index.htm. [Last accessed on 2019 Oct 03].

4. Chadda R, Sengupta S. Tobacco use by Indian adolescents. Tob Induc Dis 2002;1:111-9.

5. Das N, Tasa AS, Medhi AH. Pattern of tobacco use among adolescents in urban slums of Jorhat Assam. Int J Community Med Public Heal 2017;4:4232-7.

6. World Health Organization. India (Ages 13-15) Global Youth Tobacco Survey (GYTS).World Health Organization; 2009. Available from: https://www.who.int/fctc/reporting/ Annexoneindia.pdf. [Last accessed on 2019 Oct 03].

7. WHO India. Tobacco. World Health Organization; 2019. Available from: http://www.searo.who.int/india/topics/tobacco/ en/. [Last accessed on 2019 Oct 03].

8. Rooban T, Joshua E, Rao UK, Ranganathan K. Prevalence and correlates of tobacco use among urban adult men in India: A comparison of slum dwellers vs. non-slum dwellers. Indian J Dent Res 2012;23:31-8.

9. Khan MMH, Khan A, Kraemer A, Mori M. Prevalence and correlates of smoking among urban adult men in Bangladesh:
Slum versus non-slum comparison. BMC Public Health 2009;9. Available from: https://bmcpublichealth.biomedcentral.com/track/ pdf/10.1186/1471-2458-9-149. [Last accessed on 2019 Oct 03].

10. Gupta V, Yadav K, Anand K. Patterns of tobacco use across rural, urban, and urban-slum populations in a north Indian community. Indian J Community Med 2010;35:245-51.

11. Bardhan T, Saikia AM, Baruah R. Commentary on: Factors influencing substance use among adolescent slum dwellers of Guwahati City, Assam. J Mahatma Gandhi Inst Med Sci 2018;23:25-9.

12. Chockalingam K, Vedhachalam C, Rangasamy S, Sekar G, Adinarayanan S, Swaminathan S, et al. Prevalence of tobacco use in urban, semi urban and rural areas in and around Chennai City, India. PLoS One 2013;8:e76005.

13. Hussain CA, Hajira Saba I, Gopi A, Subramanyam G. Tobacco prevalence and usage pattern among Bengaluru urban slum dwellers. Int J Community Med Public Heal 2016;3:432-6.

14. Baruah M, Baruah KK, Ojah J, Baruah R. Prevalence of tobacco use among school going adolescents of Guwahati city, Assam. Indian J Basic Appl Med Res 2016;5:92-8.

15. Sharma R, Grover VL, Chaturvedi S. Tobacco use among adolescent students and the influence of role models. Indian $\mathrm{J}$ Community Med 2010;35:272-5.

16. Singh V, Pal HR, Mehta M, Dwivedi SN, Kapil U. Pattern of tobacco use among school children in National Capital Territory (NCT). Indian J Pediatr 2007;74:1013-20.

17. Kokiwar PR, Jogdand GR. Prevalence of substance use among male adolescents in an urban slum area of Karimnagar district, Andhra Pradesh. Indian J Public Health 2011;55:42-5.

18. Bezinović P, Malatestinić D. Perceived exposure to substance use and risk-taking behavior in early adolescence: Cross-sectional study. Croat Med J 2009;50:157-64.

19. Doubeni CA, Li W, Fouayzi H, Difranza JR. Perceived accessibility as a predictor of youth smoking. Ann Fam Med 2008;6:323-30.

20. Tun NA, Chittin T, Agarwal N, New ML, Thaung Y, Phyo PP. Tobacco use among young adolescents in Myanmar: Findings from global youth tobacco survey. Indian J Public Health 2017;61:S54-9. 